\title{
In situ green synthesis of antibacterial copper nanocomposite cotton fabrics using Achyranthes aspera leaf extract
}

\author{
Jaswanth Seetha ${ }^{1}$, Umamahesh Mallavarapu ${ }^{2 *}$, Arundathi Mesa ${ }^{3}$ \\ ${ }^{1}$ Department of Chemistry, Jawaharlal Nehru Technological University, Anantapur, Anantapuramu-515002, India. \\ ${ }^{2}$ Department of Chemistry, Rajeev Gandhi Memorial College of Engineering \& Technology, Nandyal-518501, India. \\ ${ }^{3}$ Department of Genetics and Genomics, Yogi Vemana University, Kadapa-516005, India.
}

\begin{tabular}{l}
\hline ARTICLE INFO \\
\hline Received on: 25/12/2019 \\
Accepted on: 23/03/2020 \\
Available online: 06/05/2020 \\
\hline Key words: \\
Nanocomposite cotton \\
fabrics, in situ generation, \\
Achyranthes aspera \\
leaf extract, mechanical \\
properties, antibacterial \\
activity.
\end{tabular}

\begin{abstract}
Nanomaterials are finding the diversity of application at the leading edge in emerging field of nanotechnology. Copper nanoparticles (CuNPs) were in situ generated on the surface of cotton fabrics, using Achyranthes aspera leaf extract by environmentally benign green synthesis. The structural and morphological properties of synthesized nanocomposite cotton fabrics (NCFs) were characterized by different spectral studies such as Fourier-transformation infrared (FTIR), scanning electron microscopy (SEM) coupled with energy-dispersive X-ray primary and derivative thermogravimetric (TG-DTG), differential scanning calorimetry (DSC), and X-ray diffractometer (XRD). The molecular functionalities of hydroxyl groups in polyphenols of $A$. aspera leaf extract were identified from FTIR absorption spectrum, and they are responsible for the bioreduction of $\mathrm{Cu}^{+2}$ into $\mathrm{Cu}^{0}$ for the formation of CuNPs. The average size of the formed CuNPs from SEM studies was found to be $95 \mathrm{~nm}$. The formed CuNPs were exhibited Face centered cubic (FCC) crystalline structure, and it was confirmed by XRD studies. TG-DTG analysis publicized the thermal stability of NCFs. The tensile strength of NCFs was higher than normal cotton fabrics. These NCFs exhibited good antibacterial properties which considered for making aprons and wound dressing materials in medicine and for packing materials.
\end{abstract}

\section{INTRODUCTION}

Nanocomposites are gaining importance in our daily life as an emerging field of nanotechnology, which utilizes in pharmaceutical, textile, industrial, biological, and biomedical applications (Jia et al., 2012; Zare and Shabani, 2016). In medicine, metal nanoparticles (MNPs), such as copper, silver, titanium, gold, and platinum, are showing good biological properties (Dizaj et al., 2014; Nasrabadi et al., 2016; Palza et al., 2015; Zain et al., 2014). In specific, copper nanoparticles (CuNPs) were proved to have potential antibacterial, antifungal, and mechanical properties (Bagchi et al., 2013; Viet et al., 2016). In recent times, researchers have been shifted toward bioreduction of metal ions into MNPs, due to simple, cheaper in cost, eco-friendly, and easy technique to synthesize. Now, researchers are employing bioreduction method to

\section{"Corresponding Author}

Umamahesh Mallavarapu, Department of Chemistry, Rajeev Gandhi Memorial College of Engineering \& Technology, Nandyal-518501, India. E-mail: mahesh1962rgm@gmail.com prepare MNPs, utilizing plant parts such as leaves, stem, peel, and root extracts (Dubey et al., 2010; Raut et al., 2013; Surendra et al., 2016; Tahir et al., 2015). The preparation of nanoparticles in polymer matrices results in agglomeration and apart inferior properties (Werner et al., 2008). To overcome this agglomeration, it is better to shift to an in situ generation method for preparing MNPs in cotton fabrics. Hence, researchers are using in situ generation method to synthesize the MNPs in cellulose cotton fabrics (Muthulakshmi et al., 2017; Rao et al., 2018) and prepared cellulose nanocomposite films (Sivaranjana et al., 2017). The main objective of the authors is to synthesize the copper nanocomposite cotton fabrics (NCFs), using Achyranthes aspera leaf extract at appropriate conditions.

Achyranthes aspera plant species belong to Amaranthaceae family and is widely available in Asia and Africa, commonly called as uttareni in south India. It is used for the repossession of waste fields. In India, the seeds and leaves of uttareni plant were used for human consumption and in religious ceremonies (Ragupathy et al., 2008; Ragupathy et al., 2009). In Ayurveda, it is utilized for the treatment of boils, skin eruptions, stomach ache, and piles (Dwivedi et al., 2008). The leaf extract was formed to be antiperoxidative and prothyroidic 
in rats (Tahiliani et al., 2000). Hence, the authors utilized the leaf extract of $A$. aspera as a reducing agent to generate the CuNPs in NCFs by in situ generation method. The synthesized NCFs were characterized by scanning electron microscopy (SEM) along with energy-dispersive X-ray (EDX), X-ray diffractometer (XRD), and Fourier-transformation infrared (FTIR) spectroscopy and thermal properties by derivative thermogravimetric (TGDTG) and differential scanning calorimetry (DSC) analysis. The mechanical properties such as tensile strength and tensile strain were calculated by a universal testing machine (UTM).

\section{EXPERIMENTAL}

\section{Materials}

White cloth procured from local market, penta hydrated copper sulfate $\left(\mathrm{CuSO}_{4} .5 \mathrm{H}_{2} \mathrm{O}\right)$, Sigma Aldrich, Mumbai, and $A$. aspera leaves collected from local fields were employed in the present study.

\section{Achyranthes aspera leaf extract preparation}

The fresh leaves of $A$. aspera were picked before sunrise from the plants and cleaned thoroughly several times with double distilled water to remove all the impurities such as dust and dirt present on their surface, dried, and cut in to small pieces. About $900 \mathrm{ml}$ of distilled water was taken in a cleaned glass vessel, and $100 \mathrm{~g}$ of chopped $A$. aspera leaves was weighed and poured into glass vessel. It was kept on magnetic stirrer and heated up to $80^{\circ} \mathrm{C}$ for 20 minutes with a stirring rate of $300 \mathrm{rpm}$. The obtained extract was filtered by using filter cloth followed by Whatman no. 1 filter paper, stored in reagent bottles, and kept at $4{ }^{\circ} \mathrm{C}$ in the refrigerator.

\section{Preparation of matrix}

About $250 \mathrm{ml}$ of prepared $A$. aspera leaf extract was taken in cleaned $250-\mathrm{ml}$ beakers. The washed and dried white cotton fabrics cut into pieces of $9 \mathrm{~cm} \times 27 \mathrm{~cm}$ were immersed in beakers and placed on a magnetic stirrer with a constant stirring rate of $300 \mathrm{rpm}$ in room temperature for 1 day. The leaf extract was diffused on to the surface of cotton fabrics. These cotton fabrics were removed from the leaf extract, rinsed and eroded with condensed water for more than two times to remove non-adhered organic impurities on its surface, dried, and used as a matrix.

\section{Preparation of CuNPs in matrix by in situ method}

The dissimilar concentrations of aqueous penta hydrated copper sulfate $\left(\mathrm{CuSO}_{4} .5 \mathrm{H}_{2} \mathrm{O}\right)$ precursor solutions $(250,125,25$, 5 , and $1 \mathrm{mM}$ ) were prepared. About $250 \mathrm{ml}$ of each concentrated solution was taken separately in $250-\mathrm{ml}$ beakers, and two pieces of matrices were immersed in each precursor solution. These beakers are labeled and placed on a magnetic mixer for 1 day with a mixing rate of $300 \mathrm{rpm}$ at room temperature. The color changes from greenish yellow to greenish brown. After 24 hours, these NCFs taken out, rinsed, and cleaned carefully with double distilled water most of the times and dried. After many washings, the color remains unchanged, specifying the formation of stable CuNPs in NCFs.

\section{Characterization}

The SEM pictures along with EDX of NCFs were documented, using JEOL JSM-IT500 scanning electron microscope. The FTIR spectra were recorded, using BRUKER
ALPHA-II spectrophotometer. The XRD spectrum was also carried out to validate the morphology of the prepared CuNPs in NCFs, using RIGAKU MINI FLEX 600. A standard INSTRON-3369 UTM was utilized to calculate the mechanical strength of the synthesized NCFs, for comparing matrix and white cellulose cotton fabric. The antibacterial activity of the matrix and CuNP cotton fabrics were studied for their antibacterial activity against Gram-positive and Gram-negative bacteria by standard disc method (Natarajan et al., 2005).

\section{RESULTS AND DISCUSSION}

\section{Preliminary conformation of CuNPs in NCFs}

The initial visual conformation of generated CuNPs on the surface of NCFs has done with the persistent change of color. The digital images of NCFs generated with different concentrations of source solutions $(1,5,25,125$, and $250 \mathrm{mM})$, white cellulose fabric, and matrix are shown in Figure 1. The greenish brown color intensity of the NCFs was gradually deepened with an increased concentration of source solution (Fig. 1c-g).The preliminary observation of the change of persistent color and not diminished even after several washings specifies the generation of in situ generated CuNPs in NCFs.

\section{SEM analysis}

The surface morphologies of the synthesized NCFs by in situ generation method were studied by SEM analysis. The digital SEM photographs of NCFs made using $1 \mathrm{mM}$ (minimum) and 250 $\mathrm{mM}$ (maximum) source solutions were recorded and are shown in Figure $2 \mathrm{a}$ and $\mathrm{b}$, corresponding EDX spectra in Figure $2 \mathrm{c}$ and $\mathrm{d}$, and size distribution histograms in Figure 2e and $\mathrm{f}$. The formed CuNPs in NCFs were found to be spherical in shape with an average size of $95 \mathrm{~nm}$, using Smart Tiff program. The presence of metallic copper was confirmed by the appearance of the energy peaks in the EDX spectra (Fig. 2c and d). The EDX spectrum of NCFs made using $1 \mathrm{mM}$ (minimum) showed only one peak at an energy level of $1 \mathrm{keV}$ due to the lower concentration of $\mathrm{CuSO}_{4} .5 \mathrm{H}_{2} \mathrm{O}$. However, the EDX spectrum of $250 \mathrm{mM}$ (maximum) exhibited energy band peaks at 1 and $8 \mathrm{keV}$, due to the formation of more number of CUNPs as reported by earlier workers (Sadanand et al., 2017). The remaining NCFs made using $5 \mathrm{mM}$ onward which are not shown in figure also exhibited two energy peaks at 1 and 8 $\mathrm{keV}$. Hence, the generation of CuNPs on NCFs was confirmed by SEM and EDX spectra.

\section{FTIR spectral studies}

To probe the interaction between the different molecular functionalities present in $A$. aspera leaf extract and NCFs, FTIR spectral analysis was carried out as shown in Figure 3. The spectra of white cellulose cotton fabric and matrix (Fig. 3a) were overlapping with each other, showing similar chemical groups in them. The FTIR spectra of matrix and CuNPs in NCFs of all concentrations are shown in Figure 3b. In Figure 3b, it is evident that both matrix and NCFs were exhibited a similar intensity band peak at $3,279 \mathrm{~cm}^{-1}$ corresponding to hydroxyl groups ($\mathrm{OH})$ present in polyphenolic and alcoholic compounds. The other band peak at $2,889 \mathrm{~cm}^{-1}$ is due to $\mathrm{C}-\mathrm{H}$ symmetric and asymmetric stretching of alkenes present in the leaf extract. The remaining absorption band peaks at 1,635,1,431,1,323, and $1,013 \mathrm{~cm}^{-1}$ are due to $\mathrm{N}-\mathrm{H}$ bending vibrations of amides, $\mathrm{N}-\mathrm{O}$ asymmetric 


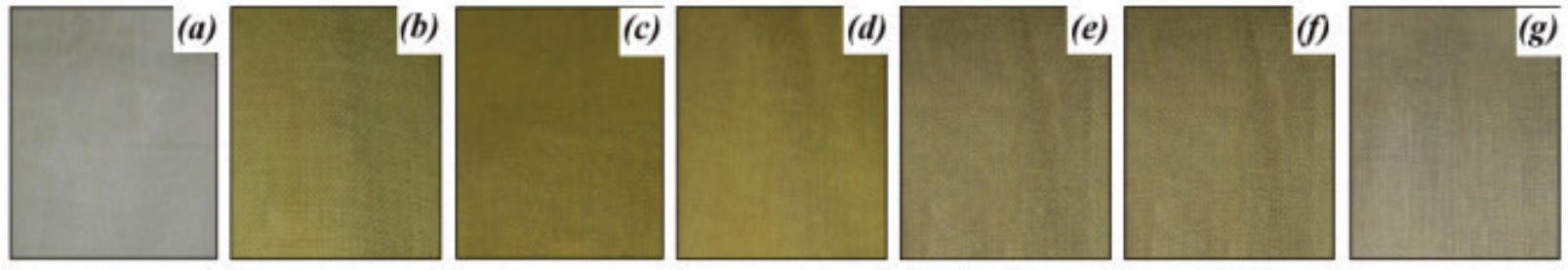

Figure 1. Digital images of (a) cellulose cotton fabric, (b) matrix, and (c-g) different concentrations of NCFs.
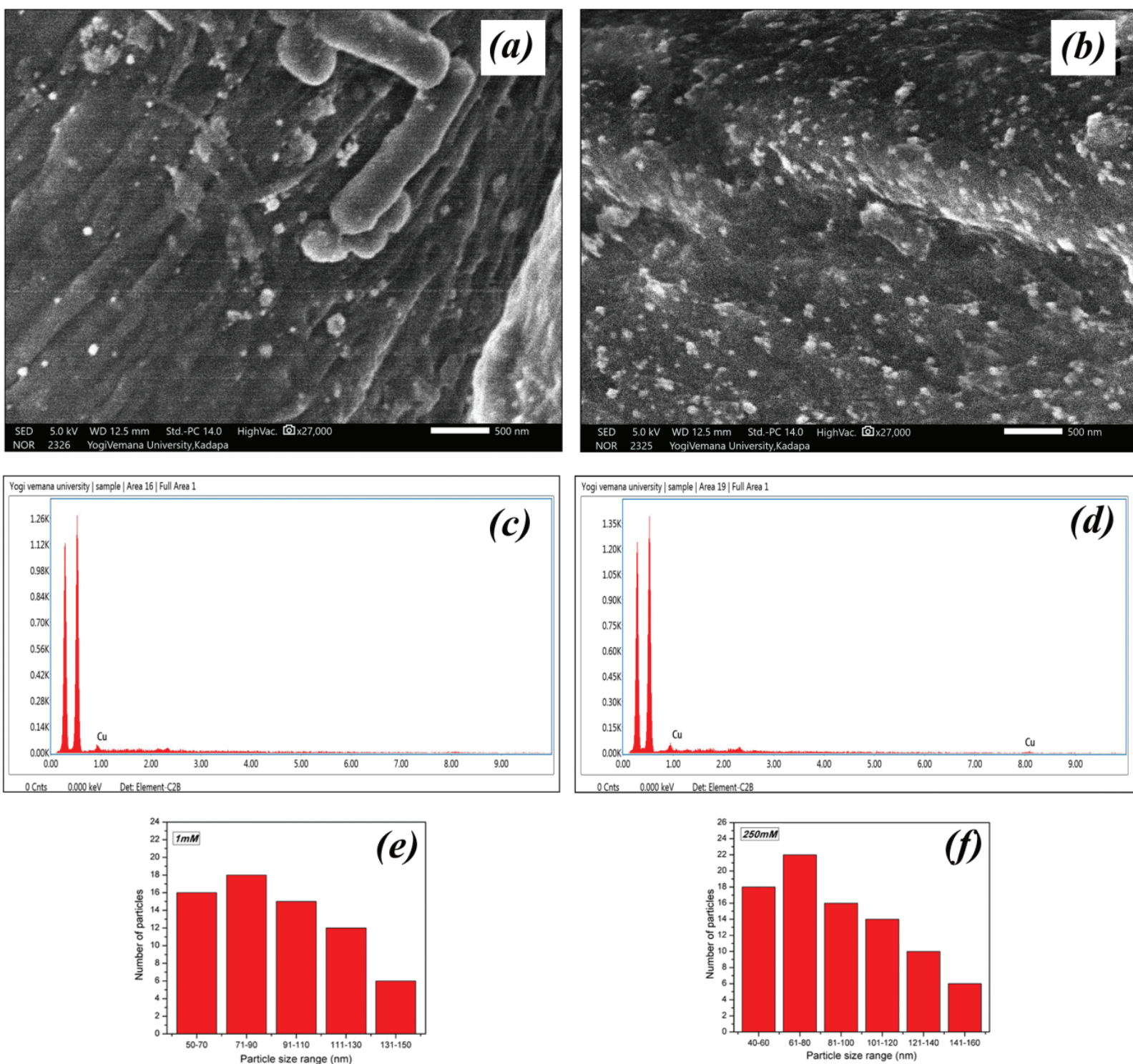

Figure 2. SEM along with EDX and histograms of NCFs made using $1 \mathrm{mM} \mathrm{(a,} \mathrm{c,} \mathrm{and} \mathrm{e)} \mathrm{and} 250 \mathrm{mM}$ (b, d, and f) $\mathrm{CuSO}_{4} \cdot 5 \mathrm{H}_{2} \mathrm{O}$ source solutions, respectively.

stretching vibrations of nitro compounds, C-N stretching vibrations of aromatic compounds, and $\mathrm{C}-\mathrm{O}$ stretching vibrations of aromatic and aliphatic compounds (Elumalai et al., 2016). These observations reveal that there will be an increase in the number of $-\mathrm{OH}$ and other functional groups in the matrix, due to the diffusion of $A$. aspera leaf extract into the cotton fabric. The increase in the number of hydroxyl functionalities in the matrix is responsible to involve the in situ generation of CuNPs in the matrix. The main absorption band peak at $3,279 \mathrm{~cm}^{-1}$ for the NCFs was lower than that of the matrix, noticing that the consumption of hydroxyl $(-\mathrm{OH})$ functional groups was reduced the $\mathrm{Cu}^{+2}$ ions into CuNPs. The same observation was reported by earlier workers (Amara et al., 2019) during the biosynthesis of CuNPs on NCFs using red sander powder extract as a reducing agent. 

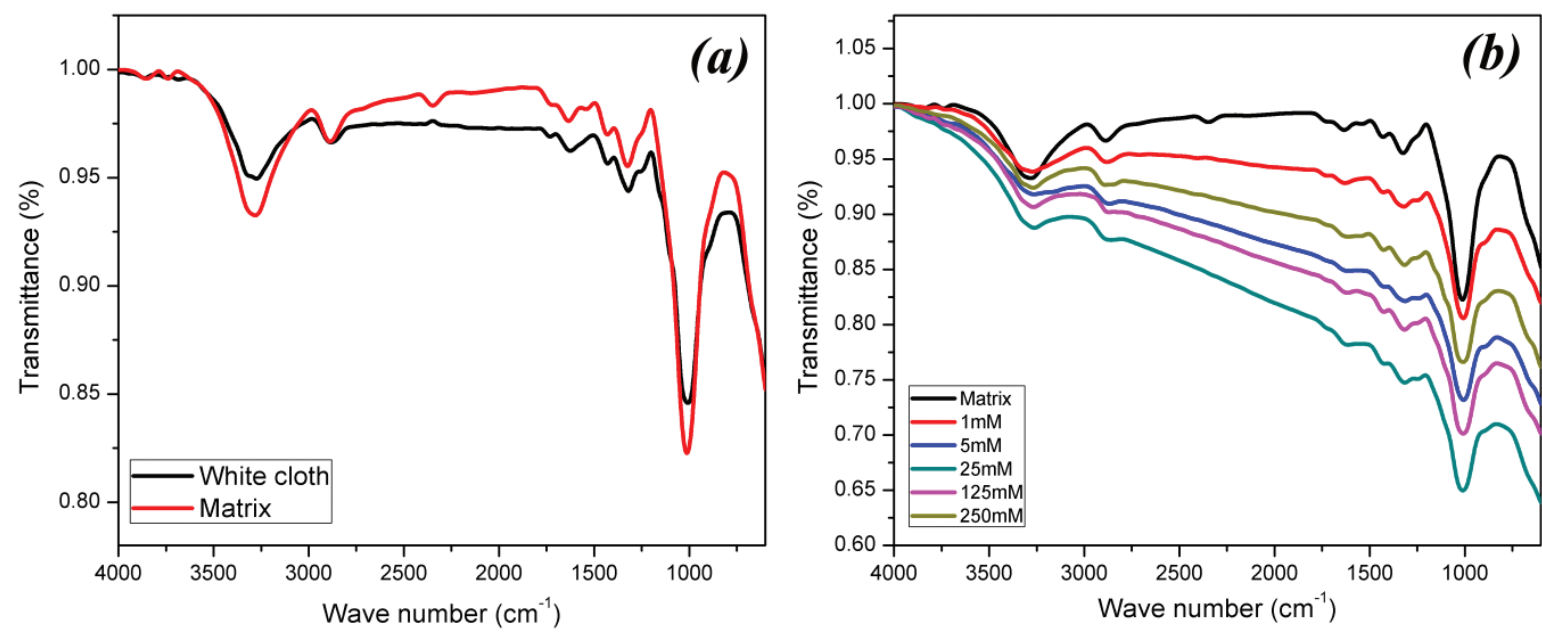

Figure 3. FTIR spectra analysis of (a) matrix and cellulose fabric and (b) NCFs (all concentrations).

\section{XRD analysis}

To study the nature of crystallinity of the generated NCFs, the XRD analysis was carried out. The recorded diffractogram of matrix and NCF made using $250 \mathrm{mM}$ (maximum) is shown in Figure 4. Both matrix and NCFs were exhibited the same peaks at $2 \theta=15.11^{\circ}, 17.01^{\circ}, 22.89^{\circ}$, and $34.28^{\circ}$, corresponding to the planes (101), (10-1), (002), and (040), respectively, related to cellulose-I structure (Zhou et al., 2017). In addition, the NCF exhibited various peaks at $2 \theta=42.59^{\circ}, 50.31^{\circ}$, and $73.18^{\circ}$, corresponding to the lattice planes (111), (200), and (220), respectively, related to CuNPs. The remaining peaks at $2 \theta=46.01^{\circ}, 64.28^{\circ}$, and $70.07^{\circ}$, corresponding to the planes (111), (200), and (220), respectively, related to $\mathrm{Cu}_{2}$ ONPs (Jadhav et al., 2011; Salavati-Niasari et al., 2009). The formed CuNPs are found to be face-centered cubic lattice structure, confirmed the formation of in situ generated CuNPs in NCFs.

\section{TG-DTG and DSC analysis}

To explain the thermal stability of formed CuNPs in NCFs, TG-DTG and DSC studies were carried out. The primary and derivative thermogram curves of NCF $[1 \mathrm{mM}$ (minimum) and $250 \mathrm{mM}$ (maximum)] source solutions and matrix are shown in Figure $5 \mathrm{a}$ and $\mathrm{b}$. Both matrix and NCFs exhibited a thermal degradation in two stages. The initial phase of deterioration was noticed between $44^{\circ} \mathrm{C}$ and $179^{\circ} \mathrm{C}$, owing to the vaporization of volatile compounds and moisture in NCFs and matrix. The next phase of degradation was detected in the temperature range of $271^{\circ}-372^{\circ} \mathrm{C}$ and $308^{\circ} \mathrm{C}-408^{\circ} \mathrm{C}$ for NCFs and matrix, respectively. In Figure $5 \mathrm{a}$ and $\mathrm{b}$, it is noticed that the thermal stability of NCFs was lesser than matrix, owing to the catalytic activity of CuNPs. A similar behavior was also noticed by earlier researchers (Sadanand et al., 2016). DSC studies were also carried along with TG-DTG to explain the phase transfer of NCFs, and the obtained DSC spectra are shown in Figure 5c. It is also revealed that the degradation of NCFs was lesser than matrix, indicating an exothermic reaction which is utilized to increase the temperature. These results confirmed that the generated CuNPs in NCFs were crystalline in nature and in accordance with X-ray diffraction spectral studies.

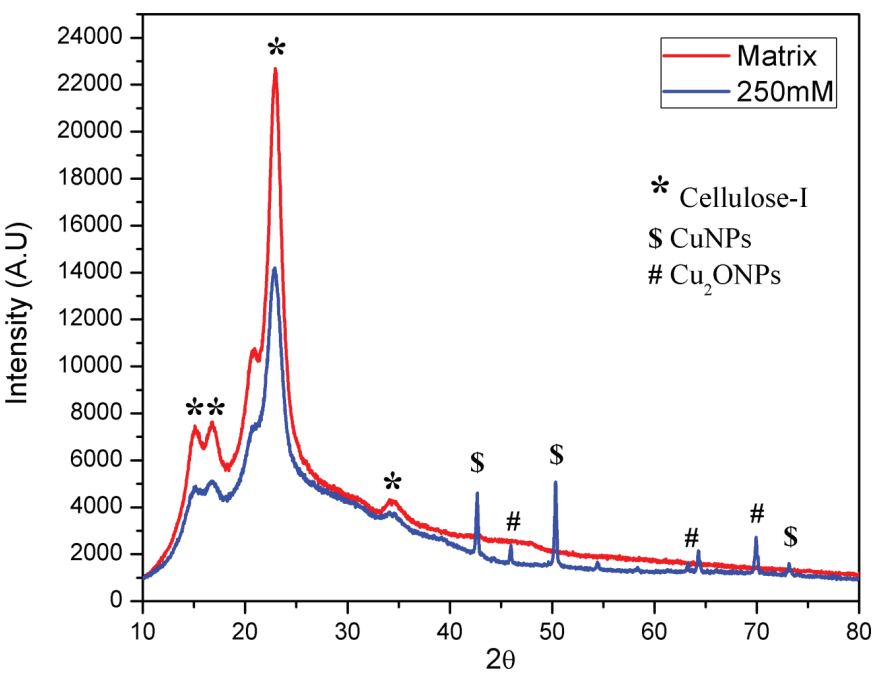

Figure 4. XRD spectra of matrix and NCF (250 mM).

\section{Mechanical properties}

In recent days, metal nanocomposite material utilization was increasing day by day, due to their high strength, smaller size, and light weight (Gouda et al., 2010; Li et al., 2015). To study the mechanical properties of the synthesized NCFs, such as high load bearing capability, tensile stress (T. stress) and tensile strain (T. strain) were measured and obtained the curves of NCFs ( 1 and $250 \mathrm{mM}$ ), white cotton cloth and matrix are shown in Figure 6, and the obtained average of three values is given in Table 1 The white cellulose cotton fabric $(\mathrm{T}$. strain $=13.56 \mathrm{MPa}$ and $\mathrm{T}$. stress $=$ $0.26 \%)$ and matrix $(\mathrm{T}$. strain $=13.43 \mathrm{MPa}$ and $\mathrm{T}$. stress $=0.24 \%)$ were exhibited almost equal tensile stress and strain values (Fig. 6), indicating that both have similar structure. The generated NCFs, such as $1-\mathrm{mM} \mathrm{NCF}$ (T. strain $=18.63 \mathrm{MPa}$ and T. stress $=0.23 \%)$ and $250-\mathrm{mM} \mathrm{NCF}$ (T. strain $=20.26 \mathrm{MPa}$ and $\mathrm{T}$. stress $=0.20 \%$ ), exhibited higher tensile stress values, compared with matrix/white cloth. The generation of CuNPs on the surface of cellulose fabrics was responsible for higher strength. The induced mechanical properties of NCFs can be employed as packaging materials. 

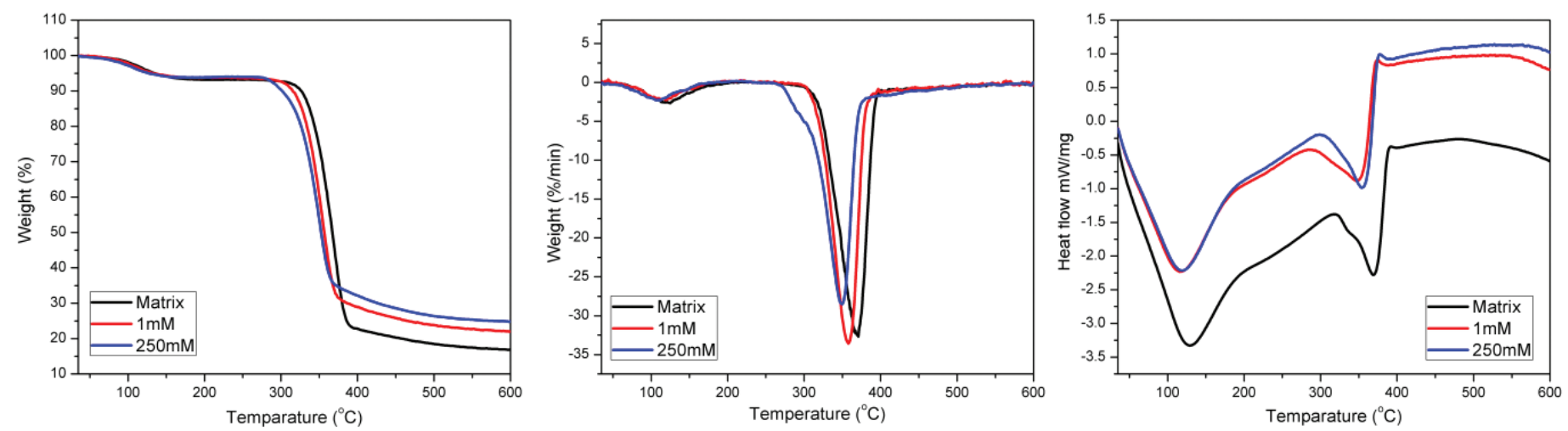

Figure 5. TG-DTG and DSC curves of matrix and NCFs (1 and $250 \mathrm{mM})$.

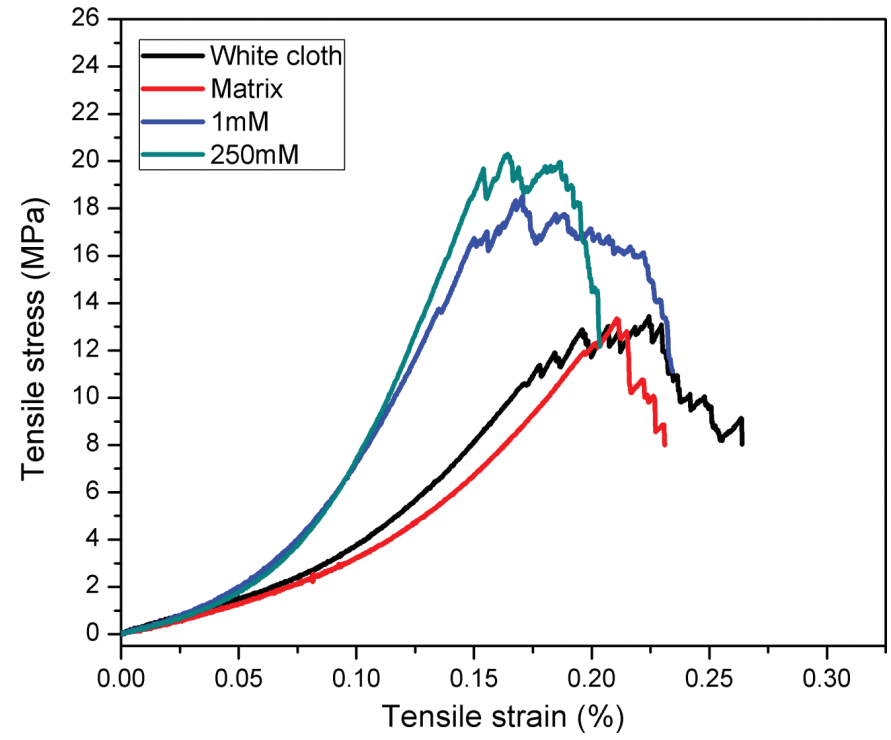

Figure 6. Mechanical properties curves of NCFs (1 and $250 \mathrm{mM})$ and matrix.

Table 1. Calculated tensile strength and stress values of NCFs at maximum loads.

\begin{tabular}{lcccc}
\hline Specimen for testing & $\begin{array}{c}\text { T. Stress } \\
(\mathbf{M P a})\end{array}$ & $\begin{array}{c}\text { T. stain } \\
(\%)\end{array}$ & $\begin{array}{c}\text { Max. load } \\
\text { (N) }\end{array}$ & $\begin{array}{c}\text { Young's Modules } \\
\text { (MPa) }\end{array}$ \\
\hline Cotton fabric & 13.56 & 0.26 & 80.66 & 111.44 \\
Matrix & 13.43 & 0.24 & 90.08 & 119.69 \\
NCF (1mM) & 18.63 & 0.23 & 101.85 & 190.85 \\
NCF (250mM) & 20.26 & 0.20 & 121.82 & 239.93 \\
\hline
\end{tabular}

\section{Antibacterial activity}

Antibacterial activity of in situ generated CuNPs on NCFs was tested by standard disc method, using Gram-positive Staphylococcus aureus and Gram-negative Pseudomonas aeruginosa bacteria. The zone of killing of both bacteria employed by NCFs using $1,5,25,125$, and $250 \mathrm{mM}$ source solutions and the comparison of white cloth and matrix are shown in Figure 7, and the measured zone of inhibition is presented in Table 2. These values reveal that the NCFs were shown a good antibacterial activity as compared with matrix, and the white cellulose fabric does not exhibited any zone of inhibition (Fig. 7). The zone of inhibition was enhanced with an increase in the concentration of

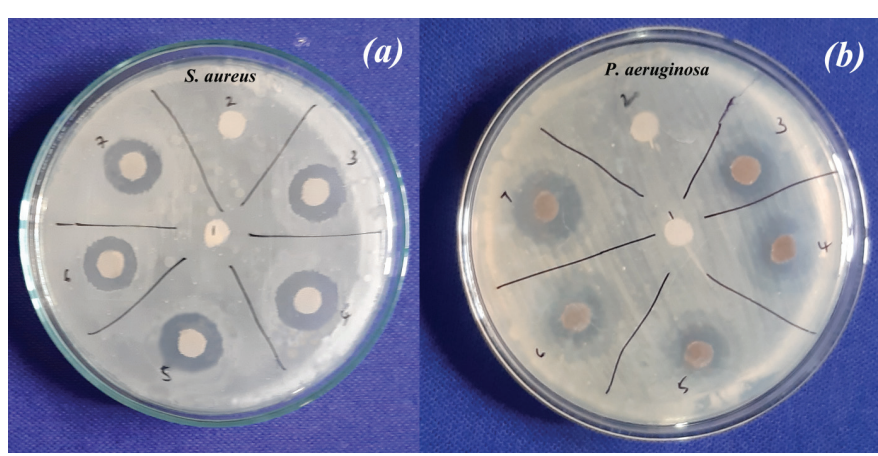

Figure 7. Antibacterial activity of NCFs and matrix against (a) P. aeruginosa and (b) S. aureus.

Table 2. Pathogenic bacteria killing zones are exhibited by NCFs against $P$. aeruginosa and $S$. aureus.

\begin{tabular}{lccc}
\hline Tester name & Number of tester & \multicolumn{2}{c}{ width of formed zone (mm) } \\
& 1 & P. aeruginosa & S. aureus \\
\hline White cloth & 2 & No formation & No formation \\
Matrix & 3 & No formation & No formation \\
$1 \mathrm{mM} \mathrm{NCF}$ & 4 & 16 & 14 \\
$5 \mathrm{mM} \mathrm{NCF}$ & 5 & 18 & 14 \\
$25 \mathrm{mM} \mathrm{NCF}$ & 6 & 18 & 13 \\
$125 \mathrm{mM} \mathrm{NCF}$ & 7 & 17 & 13 \\
$250 \mathrm{mM} \mathrm{NCF}$ & & 18 & 17 \\
\hline
\end{tabular}

source solution by both bacteria (Table 2). Due to this antibacterial property, the generated CuNPs on NCFs were utilized in pharmaceutical applications such as wound dressing, aprons, antibacterial beds, and floor cleaning items.

\section{CONCLUSION}

In this work, CuNPs were prepared on the surface of cellulose cotton fabrics, using aqueous $A$. aspera leaf extract by in situ generation method. The obtained NCFs were characterized by different spectral analyses such as SEM, EDX, TG-DTG, DSC, FTIR, and XRD and tested for the mechanical and antibacterial properties. The formed CuNPs are globular in shape with an average size of $95 \mathrm{~nm}$, proved by the SEM analysis. The confirmation of copper 
metal present in the cotton fabric by observing the energy band peak forms the EDX spectrum at 1 and $8 \mathrm{keV}$. The FTIR analysis revealed that hydroxyl functional groups present in $A$. aspera leaf extract molecularities are responsible for the bioreduction of $\mathrm{Cu}^{+2}$ into $\mathrm{Cu}^{0}$. The synthesized CuNPs in NCFs exhibited a better pathogenic bacteria killing activity against $P$. aeruginosa and $S$. aureus. Hence, these in situ generated NCFs can be utilized in medical field for making aprons, bandage cloths, napkins, and floor cleaning items and can be considering for packing materials.

\section{ACKNOWLEDGMENTS}

The authors expressed their thanks to authorities and the Department of Chemistry, RGMCET, Nandyal, for providing necessary facilities to carry out the research work.

\section{CONFLICT OF INTEREST}

The authors declare that they have no conflicts of interest.

\section{FUNDING}

None.

\section{REFERENCES}

Amara VR, Basa A, Mallavarapu UM, Vatti C, Gopireddy SV, Anumakonda V. Preparation and properties of cotton nanocomposite fabrics with in situ generated copper nanoparticles using Red sanders powder extract as a reducing agent. Inorg Nano Met Chem, 2019; 49:343-8.

Bagchi B, Kar S, Dey SK, Bhandary S, Roy D, Mukhopadhyay TK, Das S, Nandy P. In situ synthesis and antibacterial activity of copper nanoparticle loaded natural montmorillonite clay based on contact inhibition and ion release. Colloids Surf B Biointerfaces, 2013; 108:358-5.

Dizaj SM, Lotfipour F, Barzegar-Jalali M, Zarrintan MH, Adibkia K. Antimicrobial activity of the metals and metal oxide nanoparticles. Mater Sci Eng C Mater Biol Appl, 2014; 44:278-4.

Dubey SP, Lahtinen M, Sillanpää M. Green synthesis and characterizations of silver and gold nanoparticles using leaf extract of Rosa rugosa. Colloid Surface A, 2010; 364:34-1.

Dwivedi S, Dubey R, Mehta K. Achyranthes aspera Linn. (Chirchira): a magic herb in folk medicine. Ethnobot Leaflets, 2008; 2008:89.

Elumalai D, Kaleena PK, Ashok K, Suresh A, Hemavathi M. Green synthesis of silver nanoparticle using Achyranthes aspera and its larvicidal activity against three major mosquito vectors. Eng Agrc Env Food, 2016; 9:1-8.

Gouda M, Hebeish A. Preparation and evaluation of $\mathrm{CuO} /$ chitosan nanocomposite for antibacterial finishing cotton fabric. J Indus Textiles, 2010; 39:203-14.

Jadhav S, Gaikwad S, Nimse M, Rajbhoj A. Copper oxide nanoparticles: synthesis, characterization and their antibacterial activity. J Cluster Sci, 2011; 22:121-9.

Jia B, Mei Y, Cheng L, Zhou J, Zhang L. Preparation of copper nanoparticles coated cellulose films with antibacterial properties through one-step reduction. ACS Appl Matinterf, 2012; 4:2897-2.

Li R, He M, Li T, Zhang L. Preparation and properties of cellulose/silver nanocomposite fibers. Carbohydr poly, 2015; 115:269-75.

Muthulakshmi L, Rajini N, Nellaiah H, Kathiresan T, Jawaid M, Rajulu AV. Experimental investigation of cellulose/silver nanocomposites using in situ generation method. J Polym Environ, 2017; 25:1021-2.

Nasrabadi HT, Abbasi E, Davaran S, Kouhi M, Akbarzadeh A. Bimetallic nanoparticles: preparation, properties, and biomedical applications. Artif Cells Nanomed Biotechnol, 2016; 44:376-80.

Natarajan D, Britto SJ, Srinivasan K, Nagamurugan N, Mohanasundari C, Perumal G. Anti-bacterial activity of Euphorbia fusiformis - a rare medicinal herb. J Ethnopharma, 2005; 102:123-6.

Palza H. Antimicrobial polymers with metal nanoparticles. Int J Mol Sci, 2015; 16:2099-16.
Ragupathy S, Newmaster SG. Valorizing the 'Irulas' traditional knowledge of medicinal plants in the Kodiakkarai Reserve Forest, India. J Ethnobiol Ethnomed, 2009; 5:10.

Ragupathy S, Steven NG, Maruthakkutti M, Velusamy B, UlHuda MM. Consensus of the 'Malasars' traditional aboriginal knowledge of medicinal plants in the Velliangiri holy hills, India. J Ethnobiol Ethnomed, 2008; $4: 8$

Rao AV, Ashok B, Umamahesh M, Chandrasekhar V, Subbareddy GV, Rajulu AV. Preparation and properties of silver nanocomposite fabrics with in situ-generated silver nano particles using red sanders powder extract as reducing agent. Int J Polymer Anal Char, 2018; 23:493-1.

Raut RW, Haroon AS, Malghe YS, Nikam BT, Kashid SB. Rapid biosynthesis of platinum and palladium metal nanoparticles using root extract of Asparagus racemosus Linn. Adv Mater Lett, 2013; 4:650-4.

Sadanand V, Feng TH, Rajulu AV, Satyanarayana B. Preparation and properties of low-cost cotton nanocomposite fabrics with in situgenerated copper nanoparticles by simple hydrothermal method. Int $\mathrm{J}$ Polymer Anal Char, 2017; 22:587-4.

Sadanand V, Rajini N, Rajulu AV, Satyanarayana B. Preparation of cellulose composites with in situ generated copper nanoparticles using leaf extract and their properties. Carbohydrpolym, 2016; 150:32-9.

Salavati-Niasari M, Davar F. Synthesis of copper and copper (I) oxide nanoparticles by thermal decomposition of a new precursor. Mater Lett, 2009; 63:441-3.

Sivaranjana P, Nagarajan ER, Rajini N, Jawaid M, Rajulu AV Cellulose nanocomposite films with in situ generated silver nanoparticles using Cassia alata leaf extract as a reducing agent. Int J biol macromol, 2017; 99:223-32.

Surendra TV, Roopan SM. Photocatalytic and antibacterial properties of phytosynthesized $\mathrm{CeO}_{2}$ NPs using Moringa oleifera peel extract. J Photochem Photobiol B, 2016; 161:122-8.

Tahiliani P, Kar A. Achyranthes aspera elevates thyroid hormone levels and decreases hepatic lipid peroxidation in male rats. J Ethnopharma, 2000; 71:527-2.

Tahir K, Nazir S, Li B, Khan AU, Khan ZU, Ahmad A, Khan FU. An efficient photo catalytic activity of green synthesized silver nanoparticles using Salvadora persica stem extract. Sep Purif Technol, 2015; 150:316-4.

Venkateswara Rao A, Ashok B, Uma Mahesh M, Venkata Subbareddy G, Chandra Sekhar V, Venkata Ramanamurthy G, VaradaRajulu A. Antibacterial cotton fabrics with in situ generated silver and copper bimetallic nanoparticles using red sanders powder extract as reducing agent. Int J Polymer Anal Char, 2019; 24:346-4.

Viet PV, Nguyen HT, Cao TM, Hieu LV. Fusarium antifunga activities of copper nanoparticles synthesized by a chemical reduction method. J Nanomat, 2016; 2016:6.

Werner D, Hashimoto S, Tomita T, Matsuo S, Makita Y. Insitu spectroscopic measurements of laser ablation-induced splitting and agglomeration of metal nanoparticles in solution. J Phys Chem C, 2008; $112: 16801-8$

Zain NM, Stapley AG, Shama G. Green synthesis of silver and copper nanoparticles using ascorbic acid and chitosan for antimicrobial applications. Carbohydr Polym, 2014; 112:195-2.

Zare Y, Shabani I. Polymer/metal nanocomposites for biomedical applications. Mater Sci Eng C, 2016; 60:195-3.

Zhou Q, Lv J, Ren Y, Chen J, Gao D, Lu Z, Wang C. A green in situ synthesis of silver nanoparticles on cotton fabrics using Aloe vera leaf extraction for durable ultraviolet protection and antibacterial activity. Textile Res J, 2017; 87:2407-19.

How to cite this article:

Seetha J, Mallavarapu U, Mesa A. In situ green synthesis of antibacterial copper nanocomposite cotton fabrics using Achyranthes aspera leaf extract. J Appl Pharm Sci, 2020; 10(05):104-109. 